\title{
Retraction Notice to "Finite-Element Analysis of Stress and Strain in Mandibular Overdentures Supported by Splinted Versus Nonsplinted Implants" [J Long Term Eff Med Implants 28(4) (2018) 277-283].
}

Finite-Element Analysis of Stress and Strain in Mandibular Overdentures Supported by Splinted versus Nonsplinted Implants, by P Fasih, MS Monfared, A Lafzi, AM Motlagh, M Dehghan, \& F Faghani, published in Volume 28, Issue 4, pages 277-283 of the Journal of Long-Term Effects of Medical Implants. The authors of this retracted article were not the researchers who led the study described therein, and due to interdepartmental miscommunications published the information without permission from or communication with the lead researchers. The article is hereby retracted. 